\title{
Article \\ CalkGH9T: A Glycoside Hydrolase Family 9 Enzyme from Clostridium alkalicellulosi
}

\author{
Paripok Phitsuwan ${ }^{1,2, * \mathbb{D}}$, Sengthong Lee ${ }^{2} \mathbb{D}$, Techly San ${ }^{2} \mathbb{D}$ and Khanok Ratanakhanokchai ${ }^{2} \mathbb{D}$ \\ 1 LigniTech-Liginin Technology Research Group, School of Bioresources and Technology, King Mongkut's \\ University of Technology Thonburi, Bangkok 10150, Thailand \\ 2 Division of Biochemical Technology, School of Bioresources and Technology, King Mongkut's University of \\ Technology Thonburi, Bangkok 10150, Thailand; sengthong.k55132@mail.kmutt.ac.th (S.L.); \\ santechly123@gmail.com (T.S.); khanok.rat@kmutt.ac.th (K.R.) \\ * Correspondence: paripok.phi@kmutt.ac.th; Tel.: +66-247-7751
}

Citation: Phitsuwan, P.; Lee, S.; San, T.; Ratanakhanokchai, K. CalkGH9T: A Glycoside Hydrolase Family 9 Enzyme from Clostridium alkalicellulosi. Catalysts 2021, 11, 1011. https://doi.org/10.3390/catal11081011

Academic Editors: Michele C. Loewen and Peter Adewale

Received: 2 July 2021

Accepted: 17 August 2021

Published: 22 August 2021

Publisher's Note: MDPI stays neutral with regard to jurisdictional claims in published maps and institutional affiliations.

Copyright: (C) 2021 by the authors. Licensee MDPI, Basel, Switzerland. This article is an open access article distributed under the terms and conditions of the Creative Commons Attribution (CC BY) license (https:// creativecommons.org/licenses/by/ $4.0 /)$
Abstract: Glycoside hydrolase family 9 (GH9) endoglucanases are important enzymes for cellulose degradation. However, their activity on cellulose is diverse. Here, we cloned and expressed one GH9 enzyme (CalkGH9T) from Clostridium alkalicellulosi in Escherichia coli. CalkGH9T has a modular structure, containing one GH9 catalytic module, two family 3 carbohydrate binding modules, and one type I dockerin domain. CalkGH9T exhibited maximal activity at $\mathrm{pH} 7.0-8.0$ and $55{ }^{\circ} \mathrm{C}$ and was resistant to urea and $\mathrm{NaCl}$. It efficiently hydrolyzed carboxymethyl cellulose (CMC) but poorly degraded regenerated amorphous cellulose (RAC). Despite strongly binding to Avicel, CalkGH9T lacked the ability to hydrolyze this substrate. The hydrolysis of CMC by CalkGH9T produced a series of cello-oligomers, with cellotetraose being preferentially released. Similar proportions of soluble and insoluble reducing ends generated by hydrolysis of RAC indicated non-processive activity. Our study extends our knowledge of the molecular mechanism of cellulose hydrolysis by GH9 family endoglucanases with industrial relevance.

Keywords: carbohydrate binding module; crystalline cellulose; endoglucanase; processive activity

\section{Introduction}

Cellulose is the most abundant polysaccharide in plant cell walls. It is composed of glucose units linked by $\beta$-glucosidic bonds. Each glucose residue is rotated $180^{\circ}$ relative to its adjacent residues, yielding cellobiose as the structural repeating unit of cellulose [1]. In addition, this structural configuration makes the glucan chain linear. This chain linearity allows the glucan chains to contact other chains, forming intra- and inter-hydrogen bonding within and between the chains. This close association between cellulose chains results in a tightly packed, crystalline polymeric structure. This rigid and strong cellulose polymer provides structural integrity to plants and recalcitrance to microbial attack [2].

Microorganisms, including fungi and bacteria, have developed enzyme systems to gain sugar from cellulose $[1,3]$. Cellulose-degrading enzymes, or cellulases, are collectively defined as enzymes that hydrolyze $\beta$-glucosidic linked cellulose chains [1]. Indeed, cellulases contain three classes of enzymes according to their modes of actions to cleave cellulose. $\beta$-1,4-Endoglucanases (EC3.2.1.4) randomly cut the intramolecular $\beta$-1,4-glucosidic bond of cellulose chains to create new chain ends, and cellobiohydrolases or exoglucanases (EC3.2.1.91 and EC3.2.1.176) processively attack at the ends of cellulose chains to produce soluble sugars, particularly cellobiose. $\beta$-Glucosidases (EC3.2.1.21) then cleave cellobiose to yield glucose. Therefore, the synergistic interaction of three classes of cellulases are believed to completely convert cellulose to glucose $[4,5]$.

According to the Carbohydrate Active Enzyme Database (http://www.cazy.org/, accessed on 3 December 2020), cellulases are grouped into several glycoside hydrolase (GH) families based on the amino acid sequence similarity of their catalytic modules. 
Cellulases are lodged into GH families: $1,3,5,6,7,8,9,10,12,16,44,45,48,51$, and 61; among these, GH9 cellulases are distinctive from cellulases in other families [6-9]. The GH9 family exclusively contains enzymes with endoglucanase activity. Interestingly, these endoglucanases can show either processive or non-processive activities [6]. The endoglucanases with processive activity, called processive endoglucanases, behave like exoglucanases during hydrolysis of insoluble cellulose. This means that the enzymes can attach to the substrate and progressively hydrolyze it before diffusion occurs [10]. However, the catalytic performance of GH9 endoglucanases varies, and it cannot be precisely predicted by sequence similarity, as individual GH9 endoglucanases have shown different substrate preferences and diverse hydrolysis activities on different forms of cellulose [6,10-12].

In addition, several GH9 endoglucanases are modular enzymes, containing accessory modules such as immunoglobulin (Ig)-like modules, fibronectin III-like domains, and carbohydrate binding modules (CBMs) $[6,13]$. Family 3 CBMs are involved in binding to cellulose, and three major subgroups ( $3 a, 3 b$ and $3 c$ ) were classified in the family 3 CBM on the basis of primary sequence similarity [8]. Subfamilies $3 a$ and $3 b$ bind to the surface of microcrystalline cellulose strongly and promote the cellulolytic rate by concentrating the enzyme near the cellulose surface. Unlike Subfamilies 3a and 3b, subfamily $3 c$ binds weakly to cellulose due to the lack of several conserved aromatic residues that are important for the strong binding to cellulose [14]. However, CBM3c is believed to convey a single cellulose chain into the nearby catalytic domain and plays an essential role for processivity $[8,14,15]$. Therefore, the functions of these modules (immunoglobulin (Ig)-like modules, fibronectin III-like domains, and CBMs) remain unclear; however, they are believed to be helper modules that are involved in structural stability or the hydrolysis efficiency of GH9 enzymes $[10,15]$. The modular structure and functionality of GH9 endoglucanases require comprehensive investigation. In addition, a more complicated modular organization of GH9 endoglucanases exist in the genomes of some cellulosome-producing microorganisms, with a GH9 catalytic module connected downstream to two family 3 CBMs and one dockerin $[16,17]$. Unfortunately, data on the functional roles of these individual modules during cellulose hydrolysis by this GH9 theme are scarce.

Clostridium alkalicellulosi is a mesophilic bacterium collected from alkaline environments. This microorganism demonstrates high cellulose degrading activity on recalcitrant polysaccharides and algal biomass $[18,19]$. This efficient catalysis is believed to be linked to the cellulosome system, which is known to be an efficient enzyme complex for cellulose and polysaccharide degradation [18]. Nevertheless, a detailed investigation of cellulosomal elements in C. alkalicellulosi has not been performed. Recently, draft genome sequencing of $C$. alkalicellulosi was achieved, revealing many genes related to structural components essential for cellulosome assembly [20,21]. In addition, various cellulosomal GH enzymes, specifically dockerin-borne enzymes, exist in the genome. Herein, one putative cellulosomal GH9 enzyme, named CalkGH9T, from the C. alkalicellulosi genome was cloned, expressed, and biochemically characterized. This GH9 enzyme has a modular structure and demonstrated unusual enzymatic activity on cellulosic substrates, differing from previously characterized GH9 endoglucanases.

\section{Results and Discussion}

\subsection{Bioinformatics Analysis}

The genome of C. alkalicellulosi was sequenced, and analysis showed that it contained one gene, CloalDRAFT_2759, which encodes a protein belonging to glycoside hydrolase family 9 . The gene (2841 bp) was computationally translated to a protein sequence of 947 amino acids with a molecular weight of $107.5 \mathrm{kDa}$ and $\mathrm{pI}=4.52$ (https://web.expasy.org/cgi-bin/protparam/protparam/, accessed on 13 June 2019) (Figure S1). Accordingly, we designated this deduced protein CalkGH9T, and this name is used hereafter. SignalP 5.0 server analysis (http:/ /www.cbs.dtu.dk/services/SignalP/, accessed on 13 June 2019) showed the presence of an $\mathrm{N}$-terminal signal peptide in the 
polypeptide with a cleavage site between Ala34 and Asp35, indicating that CalkGH9T is secreted extracellularly. BlastP server analysis (https:/ /blast.ncbi.nlm.nih.gov/Blast.cgi, accessed on 13 June 2019) revealed the modular structural organization of CalkGH9T, which contains, from the N-terminus, one GH9 catalytic module, two family 3 CBMs (CBM3s), and one type I dockerin domain (Figure 1A). Similarly, this modular architecture is present in the genes from C. thermocellum, Acetivibrio cellulolyticus, and C. clariflavum [16,17].

A

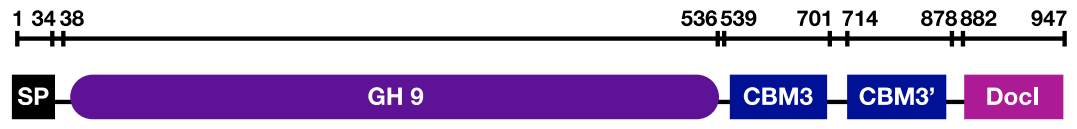

B

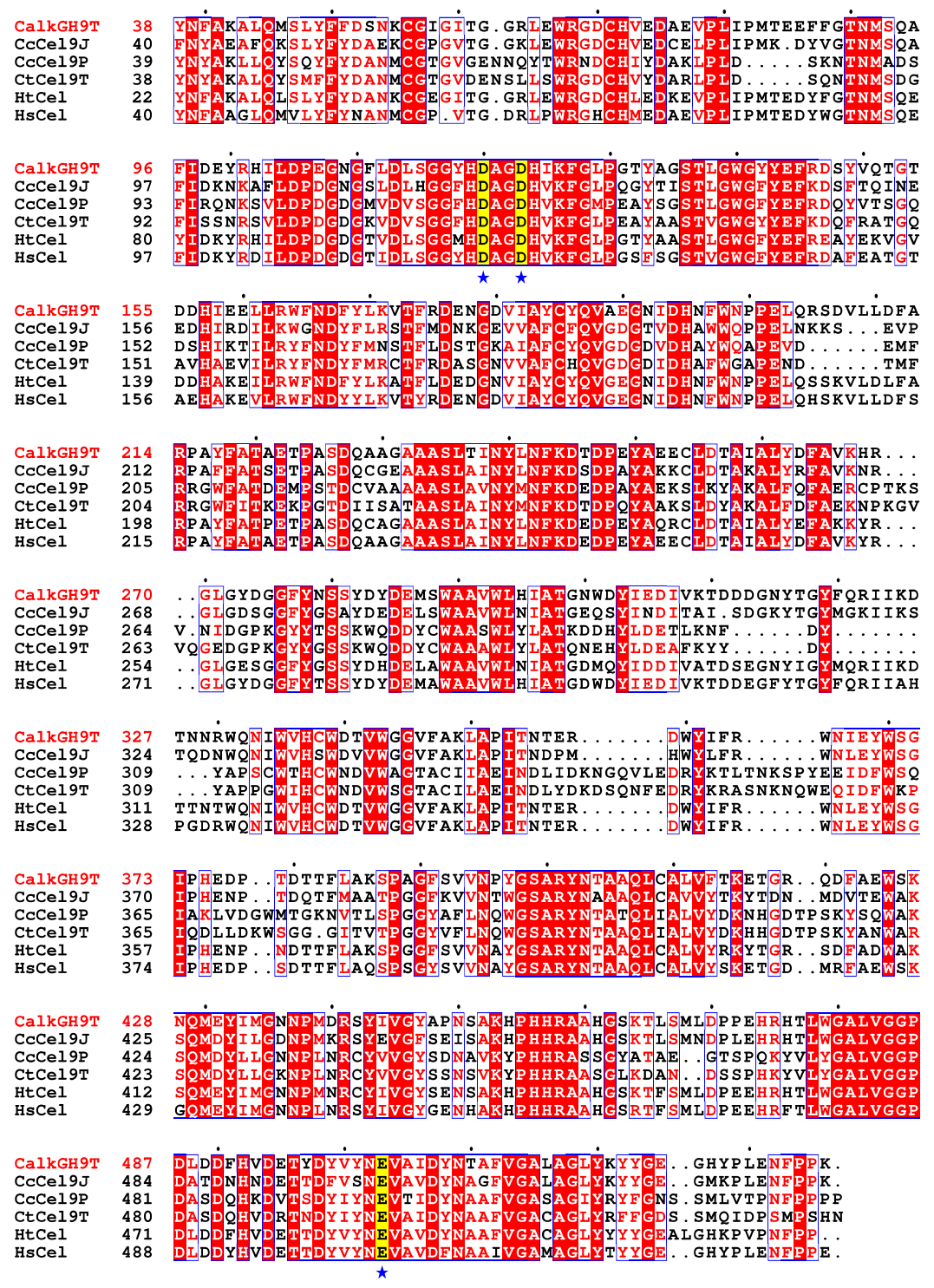

Figure 1. (A) Modular architecture of CalkGH9T, showing a full-length sequence ( 947 amino acids) starting from an N-terminal signal peptide followed by one GH9 catalytic module, two family 3 CBMs, and one dockerin. (B) Multiple sequence alignment of catalytic module of CalkGH9T and four selected GH9 enzymes. Identical residues are shown in white with a red background, whereas amino acid replacements (conservative changes) are shown in red with a white background. The three conserved catalytic residues are highlighted in yellow and marked with stars. The sequences were aligned by use of Clustal Omega [22] and the sequence alignment was displayed by using ESPript [23]. 
The sequence of the CalkGH9T catalytic module was blasted against protein sequences available in the NCBI database. The CalkGH9T catalytic module shared some similarity with endo-1,4- $\beta$-glucanases of Hungateiclostridium (formerly Clostridium) thermocellum (CAK22317.1; 81.64\%), H. saccincola (WP_101299764.1; 82.36\%), and H. straminisolven (WP_054847055.1; 80.64\%). Unfortunately, these most closely related putative enzymes have not been biochemically characterized. To identify amino acids involved in catalysis, we selected the two closest uncharacterized sequences and three known catalytic module sequences of Cel9J and Cel9P from C. cellulolyticum (CcCel9J and CcCe19P) [6] and Cel9T from C. thermocellum (CtCel9T) [24], which shared some similarity $(68 \%, 44 \%$, and 46\%, respectively) with CalkGH9T. Multiple sequence alignment of these five GH9 sequences was performed by using Clustal Omega (https:/ / www.ebi.ac.uk/Tools/msa/clustalo/, accessed on 13 June 2019), which revealed highly conserved active site regions (Figure 1B). The important catalytic amino acids were predicted to be Asp120, Asp123, and Glu504 [15]. Glu serves as a catalytic general acid, and the two Asp residues potentially bind water molecules and serve as catalytic general bases that carry out the nucleophilic attack on the $\mathrm{C} 1$ carbon of the target glucose unit, resulting in bond cleavage through an inversion-type reaction [15].

CalkGH9T contains two CBM3s, designated CalkCBM3 and CalkCBM3'. CalkCBM3 is fused to the C-terminus of GH9 catalytic module, followed by CalkCBM3'. The CalkCBM3 sequence is $29.3 \%$ and $31.5 \%$ similar to the characterized CBM3s of endoglucanases CelI and CelQ from C. thermocellum, and the CalkCBM3' sequence shares $40 \%$ and $53 \%$ similarity with the known CBM3s of the C. thermocellum CelI and Cel9V, respectively. The CelI and CelQ CBM3s adjacent to the GH9 catalytic modules belong to the type C CBM3 (CBM3c) [15,25], whereas the additional CBM3s of the C. thermocellum CelI and Cel9V belongs to type $B$ and $B^{\prime}$ CBM3 $\left(C B M 3 b\right.$ and $\left.b^{\prime}\right)$, respectively $[8,14,16]$. Unlike CBM3a or $b$, $\mathrm{CBM} 3 \mathrm{c}$ binds weakly to cellulose because of the absence of conserved aromatic residues that are involved in strong binding to cellulose. Nevertheless, some CBM3cs participate in catalytic function by facilitating cellulose decrystallization and supply the cellulose chain to the active site of the catalytic module $[25,26]$. Based on sequence similarity, CalkCBM3 and CalkCBM3' possibly show similar functions as the previously characterized CBM3c and CBM3b. However, the presence of two CBM3s in a single polypeptide suggests that individual CBM3s may have more selective roles during cellulose hydrolysis. Therefore, the functions of CalkCBM3 and CalkCBM3' remain to be studied.

A search for similarity of the CalkGH9T dockerin domain against available dockerin sequences revealed that the CalkGH9T dockerin is a type I dockerin, and it shares $62 \%$ similarity to the type I dockerin of $\mathrm{CtCel5c}$ of $C$. thermocellum [27]. Pairwise alignment showed that, like CtCel5c, CalkGH9T dockerin has conserved identical amino acids, Ser and Thr at positions 10 and 11, and similar amino acids, Arg and Arg at positions 17 and 18 (Lys and Arg are at the same positions in CtCel5c dockerin). However, the amino acid at position 22 of CalkGH9T dockerin is Glu, whereas that of CtCel5c dockerin is Arg (Figure 2). The amino acids at these positions (10,11, 17, 18 and 22) serve for binding recognition residues to interact with cohesin modules. Dockerin sequences are highly conserved within cellulosome producing microorganisms, and some dockerin sequences are very species-specific [20]. The function of type I dockerin is to dock the enzymatic subunit to the scaffolding protein to form a cellulosome complex. Our results indicate that dockerin-borne CalkGH9T is a cellulosomal enzymatic subunit of the C. alkalicellulosi cellulosome, and it possibly shows cross-reactivity with C. thermocellum cellulosome based on sequence similarity [21]. 


\section{CalkGH9T_DocI \\ CtCe15c_DocI

\author{
CalkGH9T_DocI \\ CtCel5c_DocI
}

\section{GDLNGDGRINSTDYVLLRRYILE ||$:||||:|||||\ldots:|:||||$. GDVNGDGKINSTDCTMLKRYILR}

Figure 2. Pairwise alignment of CalkGH9T and CtCel5c dockerin modules. The sequences were aligned by use of EMBOSS Needle. The amino acid residues involved in $\mathrm{Ca}^{2+}$-binding loops are highlighted in cyan, and those involved in binding recognition with cohesin are highlighted in magenta.

\subsection{Protein Expression and Purification}

The gene encoding CalkGH9T, without a signal peptide, was subcloned and expressed in competent $E$. coli BL21 (DE3) cells at $16{ }^{\circ} \mathrm{C}$. The protein was expressed in a soluble form and purified with an $\mathrm{Ni}^{2+}$-NTA column, as it contained N-terminal His-tag. The size and purity of the purified CalkGH9T was determined by SDS-PAGE, which showed a single band with an estimated size of $107 \mathrm{kDa}$ (Figure S2). The apparent molecular weight is consistent with the size deduced from the translated gene, and the full-length sequence of CalkGH9T was used for biochemical study.

\subsection{Substrate Preference and Effects of $\mathrm{pH}$ and Temperature on Enzyme Activity}

The enzymatic activity of CalkGH9T on polysaccharides was investigated (Table 1). Here, we used CMC, an ionic carboxymethyl cellulose with degree of substitution of about 0.4 , as a soluble substrate for detecting endoglucanase activity. RAC and Avicel, the insoluble substrates that contain amorphous fractions and crystallinity (70\%) [28], were used for detecting cellulase and exo-glucanase activities, respectively [29]. Xylan, a partially acetylated $\beta$-(1,4)-linked xylose monosaccharides, contain both soluble and insoluble forms. This substrate was used for detecting endo-xylanase activity, as this substrate shares similar $\beta$-1,4-glycosidic bonds in its main chain to cellulose. The results indicated that CalkGH9T had the highest activity towards CMC (Table 1). The activity on RAC was low, and the activity on Avicel was undetectable. CalkGH9T showed side-activity on xylan. This result suggests that CalkGH9T seems to hydrolyze $\beta-1,4$ linked glucan and xylan substrates. However, insoluble and crystalline forms of the substrates likely restrict the enzymatic activity. Based on this evidence, CMC was used as a substrate for further characterization.

Table 1. Substrate preference of CalkGH9T.

\begin{tabular}{ccccc}
\hline Substrate & Main Linkage & Solubility in Water & $\begin{array}{c}\text { Activity }(\mu \mathrm{M} \\
\text { Product/min/ } \boldsymbol{\mu M} \\
\text { Protein) }\end{array}$ & $\begin{array}{c}\text { Relative } \\
\text { Activity (\%) }\end{array}$ \\
\hline CMC & $\beta-1,4$ glucan & Soluble & 1021 & 100 \\
RAC & $\beta-1,4$ glucan & Insoluble & $142^{1}$ & 14 \\
Avicel & $\beta-1,4$ glucan & Insoluble & $\mathrm{ND}^{2}$ & $\mathrm{ND}$ \\
Xylan & $\beta-1,4$ xylan & In/soluble & 261 & 26 \\
\hline
\end{tabular}

${ }^{1}$ Enzymatic assay for RAC was incubated for $3 \mathrm{~h}$ with enzyme load of $1 \mu \mathrm{M} .{ }^{2} \mathrm{ND}$, no detectable activity at the assay conditions for $24 \mathrm{~h}$ with enzyme load of $1 \mu \mathrm{M}$.

Analysis of the effects of $\mathrm{pH}$ and temperature on enzymatic activity was performed using CMC as a substrate. CalkGH9T was active over a $\mathrm{pH}$ range of $5.0-11.0$ at $55{ }^{\circ} \mathrm{C}$ (Figure 3A). CalkGH9T showed more than $80 \%$ of its maximal activity at pH 7.0-8.0, with the highest activity $(100 \%)$ at $\mathrm{pH} 7.4$. The activity sharply decreased when the $\mathrm{pH}$ increased from 8.0 to 11.0. However, the enzyme remained active at $\mathrm{pH} 10.0$, with $50 \%$ residual activity. To test the stability of CalkGH9T in various $\mathrm{pH}$ environments, the enzyme was 
incubated in different buffers ( $\mathrm{pH} 3.0-11.0$ ) at $30^{\circ} \mathrm{C}$ for $1 \mathrm{~h}$ prior to incubation with CMC (Figure 3B). CalkGH9T showed good stability in the $\mathrm{pH}$ range of 7.0-9.0, and the activity gradually decreased outside this $\mathrm{pH}$ range. The $\mathrm{pH}$ profile and stability results indicate that CalkGH9T functions better in near neutral or slightly alkaline environments.

A

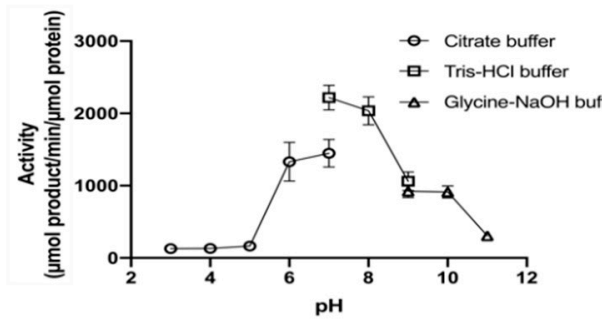

C

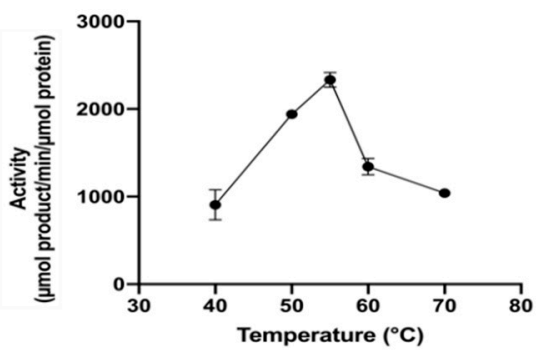

E

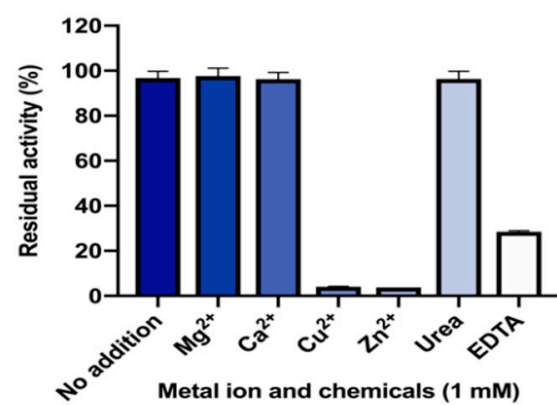

B

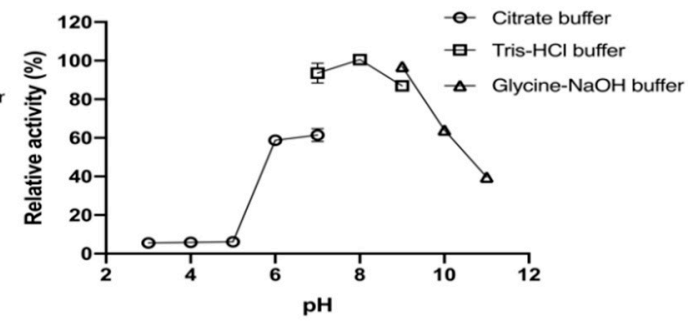

D

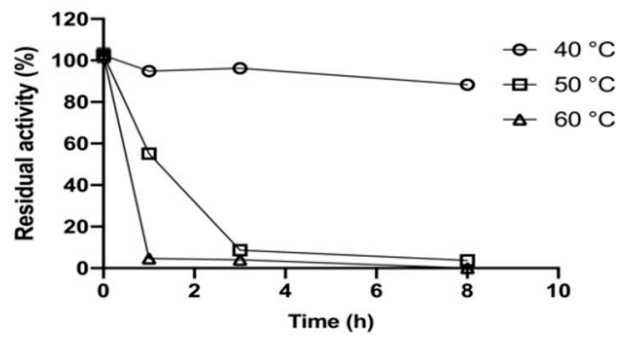

$\mathbf{F}$

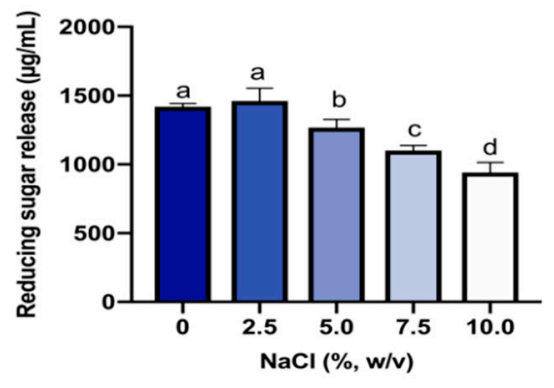

Figure 3. Biochemical properties of CalkGH9T. (A) Profiles of $\mathrm{pH}$ on activity and (B) $\mathrm{pH}$ stability assayed at $55^{\circ} \mathrm{C}$. (C) Influence of temperature on and (D) thermostability analysis of the activity of CalkGH9T assayed at $\mathrm{pH}$ 7.4. For $\mathrm{pH}$ and temperature assays, the maximum activity was considered $100 \%$; for $\mathrm{pH}$ and temperature stability assays, the enzyme activity without any treatments was considered $100 \%$. (E) Effects of metal ions and (F) NaCl on CalkGH9T activity. The enzymatic reaction was tested with $1 \%(w / v)$ CMC. Values are means and bars represent the standard deviations for three independent experiments. For $\mathrm{NaCl}$ study, different letters within bars indicate significant differences $(p<0.05)$ between the means of glucose concentrations as analyzed by Tukey's test of multiple comparisons after ANOVA test.

CalkGH9T was active over a temperature range of $30-70{ }^{\circ} \mathrm{C}$ at $\mathrm{pH} 7.4$ (Figure $3 \mathrm{C}$ ). The activity increased as a function of temperature, and the maximal activity $(100 \%)$ occurred at $55{ }^{\circ} \mathrm{C}$. The activity was lower with temperatures over $60{ }^{\circ} \mathrm{C}$, but the enzyme retained approximately $40 \%$ residual activity at $70{ }^{\circ} \mathrm{C}$. At $80{ }^{\circ} \mathrm{C}$, CalkGH9T had completely lost its activity. The thermal stability was investigated because it is a key factor for enzymes used in industrial applications. CalkGH9T was incubated at three temperatures: 40, 50, and $60{ }^{\circ} \mathrm{C}$ (Figure 3D). CalkGH9T was highly stable at $40^{\circ} \mathrm{C}$; prolonged incubation up to 
two days did not significantly diminish the activity (data not shown). The half-lives of CalkGH9T at 50 and $60{ }^{\circ} \mathrm{C}$ were $1.5 \mathrm{~h}$ and $42 \mathrm{~min}$, respectively. Our results indicate that CalkGH9T functions best at a moderate temperature.

\subsection{Effect of Metal Ions and Chemicals}

The influence of metal ions $(1 \mathrm{mM})$ on the activity of CalkGH9T against CMC was tested (Figure 3E). CalkGH9T activity was strongly inhibited by $\mathrm{Cu}^{2+}$ and $\mathrm{Zn}^{2+} . \mathrm{Mg}^{2+}$ and $\mathrm{Ca}^{2+}$ did not show any inhibitory effects on CalkGH9T activity. Urea did not decrease the activity of CalkGH9T, but EDTA remarkably decreased the activity, resulting in 25\% residual activity. It has been reported that $\mathrm{Ca}^{2+}$ is necessary for $\mathrm{GH} 9$ enzymes because it is involved in conformational stability and catalysis [9,30]. In addition, CalkGH9T contains one dockerin and two CBMs that require $\mathrm{Ca}^{2+}$ to stabilize their structures $[8,20]$. The addition of EDTA may chelate with metal ions, thus decreasing overall structural stability and activity of the enzyme.

\subsection{Effect of $\mathrm{NaCl}$ Concentration}

The activity of CalkGH9T on CMC in the presence of $\mathrm{NaCl}$ was investigated because C. alkalicellulosi was collected from a soda lake, which has high salinity (up to 2.4\%) [19] (Figure 3F). The activity of CalkGH9T without added $\mathrm{NaCl}$ was taken as $100 \%$. CalkGH9T showed great resistance to $\mathrm{NaCl}$. $\mathrm{NaCl}$ concentration in a range of $1-5 \%(w / v)$ did not significantly affect the enzyme activity. At $7.5 \%$ and $10 \%(w / v) \mathrm{NaCl}$, CalkGH9T retained more than $80 \%$ activity. This result indicates that, unlike common cellulases, high salinity does not strongly inhibit the catalytic efficiency of CalkGH9T [31,32]. This suggests that CalkGH9T is halotolerant. The high-salt resistance may be in part explained by the fact that the catalytic domain of CalkGH9T is rich in acidic amino acids (Figure S1). The distribution of the excess charges on the protein surfaces might prevent aggregation and/or precipitation induced by a high concentration of salts [33].

\subsection{Mode of Action}

\subsubsection{Activity on Polysaccharides}

To characterize hydrolysis by CalkGH9T, the profile of CMC hydrolysis was studied (Figure 4A). The release of reducing sugar increased with hydrolysis time. The rate of reducing sugar release reached a plateau after $3 \mathrm{~h}$. After that, reducing sugar release was steady. The constant release of reducing sugar may be in part explained by end-product inhibition. In addition, the activity of the enzymes was abolished when the temperature was at $50{ }^{\circ} \mathrm{C}$ or higher after 3-h incubation (Figure 3D). Therefore, the constant release of reducing sugar by CalkGH9T at $55{ }^{\circ} \mathrm{C}$ after $3 \mathrm{~h}$ could be due to the loss of enzyme activity and stability.

The reducing sugars released from CMC by CalkGH9T were analyzed by TLC (Figure 4B). The initial hydrolysis of CMC was considered to occur within $5 \mathrm{~min}$. At $1 \mathrm{~min}$, cellotetraose appeared as the initial hydrolysis product. From 1 to $5 \mathrm{~min}$, cellodextrins with various degrees of polymerization arose. The series of the hydrolysis oligomers produced indicates an endo-acting mode for CalkGH9T. However, at different time points from $1 \mathrm{~min}$ to $16 \mathrm{~h}$, cellotetraose (G4) existed as the major hydrolysis product throughout the course of hydrolysis, and other oligosaccharides, including cellopentaose (G5), cellotriose (G3), cellobiose (G2), and glucose (G1), appeared as minor hydrolysis products. Larger cellodextrins (>G5) were not observed. The high accumulation of G4 during CMC hydrolysis suggests that CalkGH9T is a cellotetraose producer with an endo-acting mode of action. On the other hand, a small amount of glucose was observed after $3 \mathrm{~h}$ of hydrolysis. The slight release of glucose is possibly a result of partial hydrolysis of some cellodextrins, such as cellopentaose (see results in Section 2.6.2). 
A

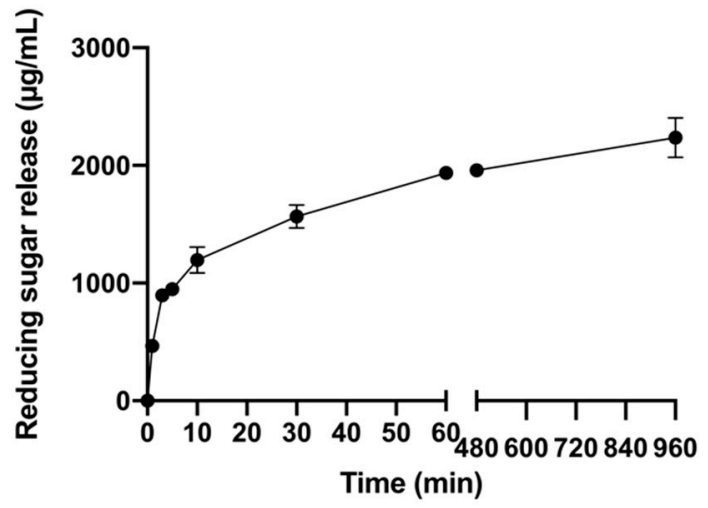

B

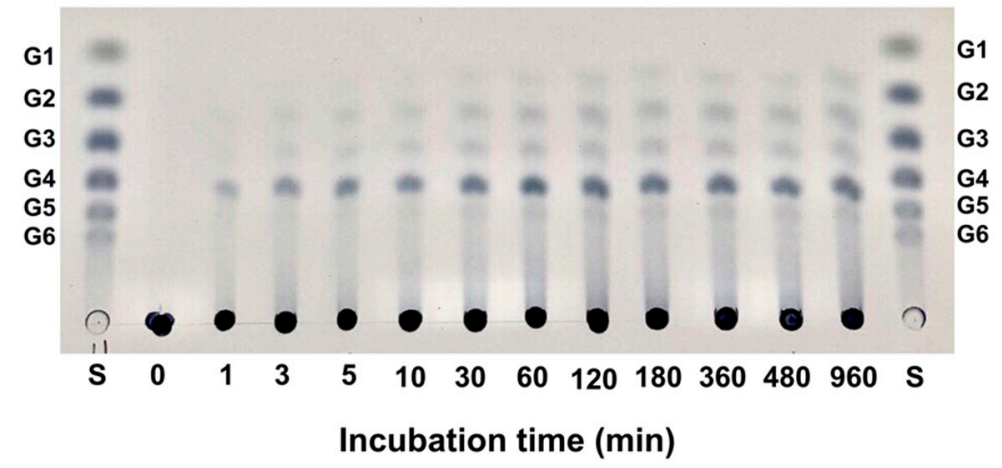

C

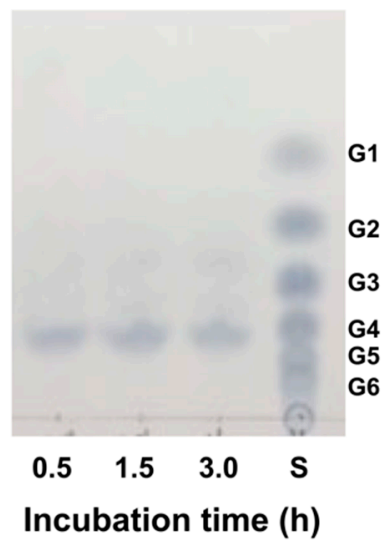

Figure 4. (A) Time course of reducing sugar release by $0.25 \mu \mathrm{M}$ CalkGH9T using CMC as the substrate. The hydrolysis reactions between 60 to 480 min were analyzed; however, the X-axis break was used to enhance the readability for the chart. (B) TLC analysis of the hydrolysis products using CMC as the substrate. (C) TLC analysis of soluble sugars derived from RAC hydrolysis by $1.0 \mu \mathrm{M}$ CalkGH9T. The enzymatic reactions of CMC and RAC were performed at $\mathrm{pH} 7.4$ and $55^{\circ} \mathrm{C}$. The samples of soluble sugars from RAC hydrolysis were concentrated by evaporation prior to being spotted on TLC. S, standards of glucose and cellodextrins with a degree of polymerization of 2-6 (G2-G6).

Unlike CMC, hydrolysis of RAC by CalkGH9T at $0.25 \mu \mathrm{M}$ enzyme load from 1 to $16 \mathrm{~h}$-incubation did not result in any detectable sugar release. To confirm this, the enzyme load was increased to $1.0 \mu \mathrm{M}$ (a 4-fold increase), and the reaction was incubated for $0.5,1.5$, and $3 \mathrm{~h}$. Nevertheless, the amount of sugar release from RAC was very small $(0.1-0.2 \mathrm{mg} / \mathrm{mL})$, and there was no significant difference in sugar concentrations at the three incubation times tested (Figure S3). The low activity on RAC indicates that insoluble amorphous cellulose is not a preferable substrate for CalkGH9T. To determine the reducing 
sugar produced, the supernatant was concentrated by evaporation and analyzed via TLC. Like CMC hydrolysis, G4 appeared as the main product (Figure 4C).

\subsubsection{Activity on Cellodextrins}

To understand more about cleavage patterns of CalkGH9T, the hydrolysis of cellodextrins (G6-G2) was studied (Figure 5). Within 5 min of hydrolysis, CalkGH9T completely hydrolyzed G6 to G4 and G2 and partially hydrolyzed G5 to G4 and G1. However, G4, G3, and G2 were not hydrolyzed (Figure 5. This result indicates the preferential cleavage of long chain oligomers. With prolonged incubation time (16 h), the hydrolysis of G5 was incomplete, leaving G5, G4, and G1. Nevertheless, no hydrolysis of G4, G3, and G2 was observed). This result indicates that G4, G3, and G2 are potential end-products of CalkGH9T (Figure S4). The active sites might contain at least six binding subsites.

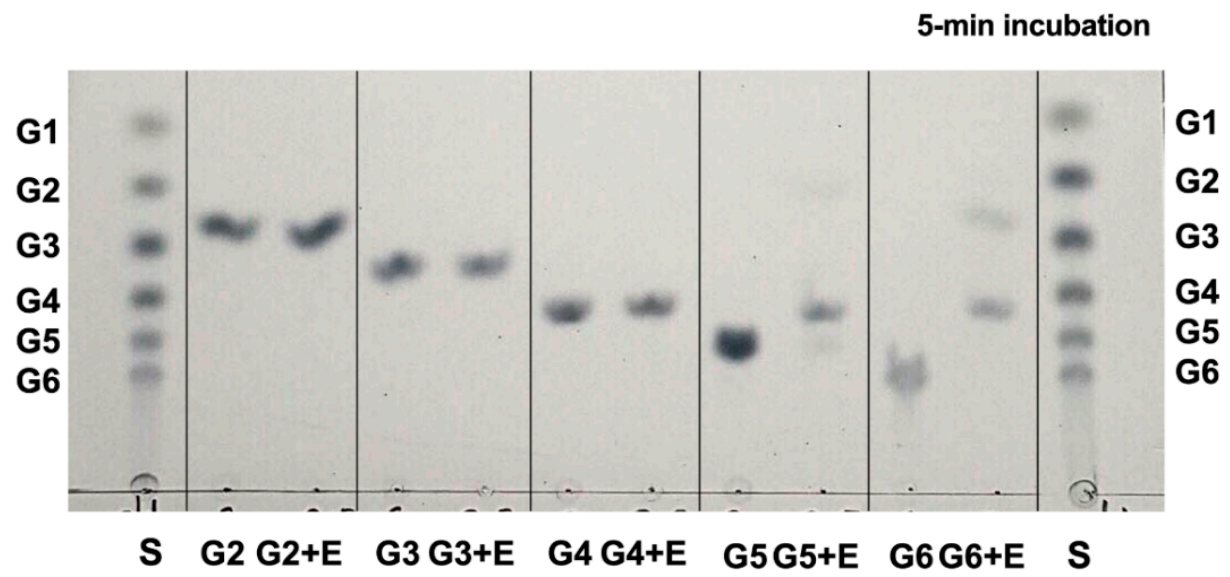

Figure 5. TLC analysis of hydrolysis products generated by $0.25 \mu \mathrm{M}$ CalkGH9T using cellodextrins with a degree of polymerization of 2-6 (G2-G6) as the substrates for 5-min incubation. S, standards of glucose and cellodextrins with a degree of polymerization of 2-6 (G2-G6). E, CalkGH9T. G2, G3, G4, G5, and G6 represent a reaction control (a reaction mixture containing a substrate and a denatured enzyme). G2 + E, G3 + E, G4 + E, G5 + E, and G6 + E represent enzymatic reactions. The enzymatic reactions were performed at $\mathrm{pH} 7.4$ and $55^{\circ} \mathrm{C}$.

\subsection{Cohesin-Dockerin Interaction}

The unique feature of cellulosome assembly is the interaction of enzyme borne dockerins and cohesin containing scaffolds [20]. The primary scaffold, named ScaA, of C. alkalicellusi cellulosome contains 10 type I cohesin modules (Figure 6A) [21], and it was selected because it was a core protein that integrates the key cellulosomal enzymes [21]. To prove the type I dockerin of CalkGH9T is functionally active, the dockerin module and four cohesin modules of ScaA were expressed and tested for binding interaction. These four cohesin modules were selected according to their difference in sequence similarity [21]. Based on the affinity-based ELISA assay, the type I dockerin of CalkGH9T bound significantly to four selected cohesin modules of ScaA (Figure 6B), indicating that CalkGH9T is an enzymatic subunit of the C. alkalicellusi cellulosome. The CalkGH9T dockerin exhibited a relatively higher affinity to the cohesin module I (ScaA-1) than ScaA-4, 5, and 10. This difference may reflect the difference in cohesin-dockerin recognition. A similar phenomenon was observed in Clostridium clariflavum [34] and Acetivibrio cellulolyticus [35], in which the dockerins of the cellulosomal enzyme subunits bind to different cohesin modules of the primary scaffold with different binding intensities. 
A

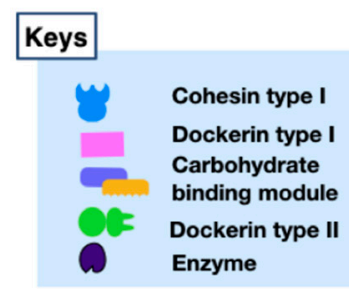

ScaA

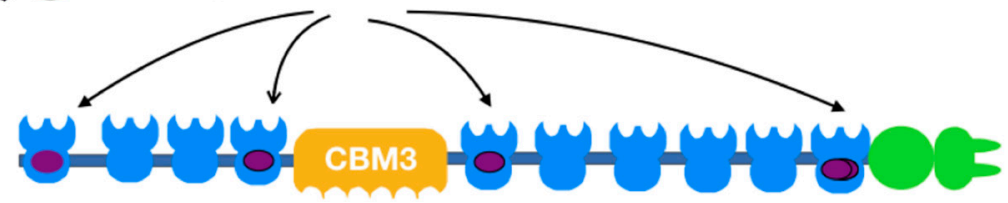

B

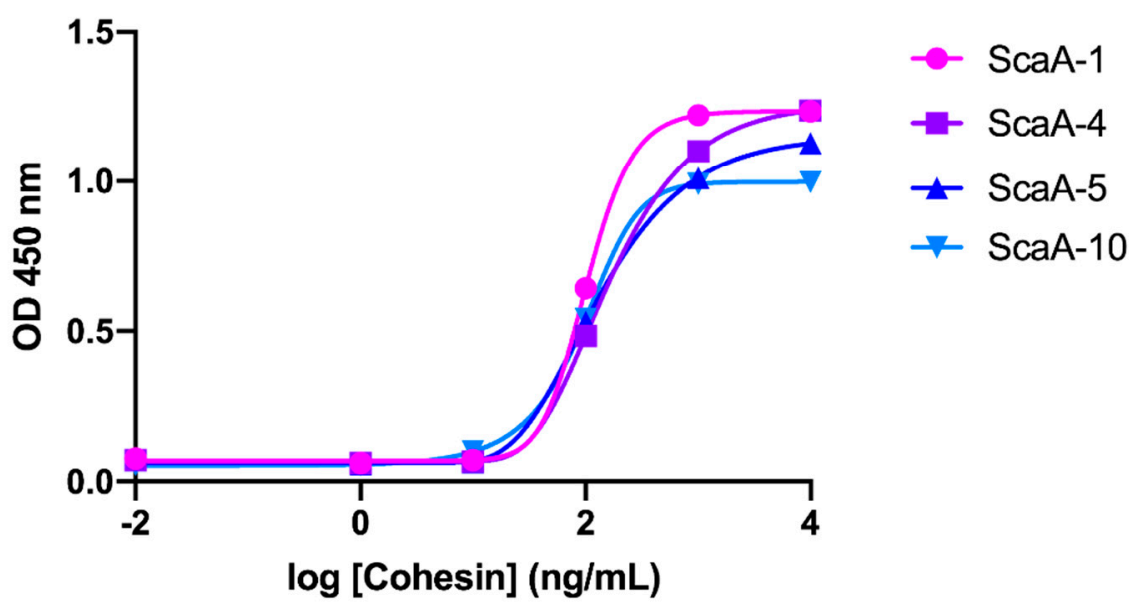

Figure 6. Binding interaction of the type I dockerin of CalkGH9T and the cohesins modules of the primary scaffold ScaA of C. alkalicellulosi cellulosome. (A) Schematic representation of CalkGH9T showing a modular architecture and ScaA containing 10 cohesin modules. Dots indicate the cohesin modules that were expressed for affinity binding test. (B) Affinity-based ELISA profiles the dockerin towards different ScaA cohesin modules. ScaA-1, 4, 5, and 10 refer to of cohesin modules 1, 4, 5 , and 10 of ScaA, and the designated numbers of the cohesin modules begin from the cohesin at the N-terminus.

\subsection{Binding Ability to Polysaccharides}

We performed an in vitro binding ability test of CalkGH9T with amorphous insoluble cellulose RAC, crystalline cellulose Avicel, and xylan because CalkGH9T contains family 3 CBMs that are known to potentiate the activity of cognate catalytic modules against insoluble substrates (Figure 7A). Here, CalkGH9T was allowed to bind with RAC, Avicel, and xylan at $4{ }^{\circ} \mathrm{C}$ for $1 \mathrm{~h}$. After binding, the samples were centrifuged to separate unbound (supernatant) and bound (associated with the substrate) fractions. Individual fractions were analyzed on SDS-PAGE. CalkGH9T appeared in the bound fractions of RAC (52\%) and Avicel (nearly 100\%), indicating the ability to bind both insoluble amorphous and crystalline cellulose. However, a higher intensity protein band occurred in the Avicelbound fraction, reflecting the ligand recognition of the CBMs, which prefer to bind the surfaces of crystalline cellulose. This strong binding ability is linked to the presence of CalkCBM3(s). In contrast, CalkGH9T was unable to bind xylan. It should be noted that although CalkGH9T contains CBM3c (CalkCBM3), which has been reported to facilitate 
cellulose disruption and continuously feed the cellulose chain to the catalytic module, the processivity of the enzyme cannot be predicted by the presence of the CBMs.

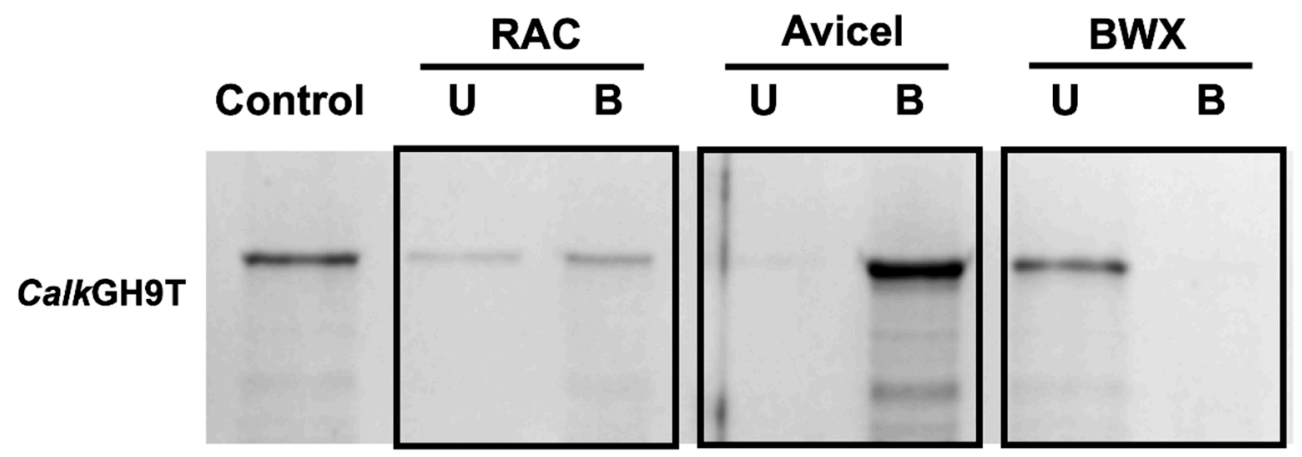

Figure 7. Binding ability of CalkGH9T to RAC, Avicel, and BWX. U and B refer to unbound and bound proteins, respectively.

\subsection{Processive Activity}

In the present study, although CalkGH9T bound tightly to Avicel, it lacked the ability to hydrolyze this microcrystalline cellulose. Therefore, RAC was used for the processivity assays because it is a suitable substrate to distinguish processive from non-processive activity [36].

Processive activity is when the enzyme remains bound to the substrate and continuously performs subsequent catalysis before dissociation. In addition, processive endoglucanase enzymes demonstrate both endoglucanase and exoglucanase activities. The exoglucanase activity releases soluble reducing sugars from insoluble cellulose into the solution; in contrast, the endoglucanase activity randomly cleaves the cellulose chain and leaves several reducing ends attached on the insoluble substrate. Therefore, the ratio of soluble and insoluble reducing ends is commonly used to differentiate exoglucanases from endoglucanases $[13,37]$. Here, we determined the distributions of reducing ends between soluble (released sugars) and insoluble (pellet) fractions of hydrolysis of RAC by CalkGH9T (Figure 8. The ratios of soluble to insoluble reducing ends did not increase as hydrolysis time was prolonged from 0.5 to $3.0 \mathrm{~h}$. This proportion (approximately 0.8 ) is similar to that found for GH9 endoglucanases from C. celllulolyticum, with proportions ranging from 0.5 to 1.2 [6]. In addition, the percentage of reducing ends ( $40 \%)$ produced from the insoluble RAC is common for endoglucanase activity and it is consistent with other true endoglucanases that produce approximately 30 to $50 \%$ reducing ends from insoluble substrates $[37,38]$. This result indicates that CalkGH9T is an endoglucanase with non-processive activity.

\subsection{Addition of CalkGH9T to a Fungal Enzyme Preparation}

Based on substrate specificity and hydrolysis product generation, CalkGH9T appears to have different mode of action compared to common fungal endoglucanases [39] and it contains the CBM3c, which is reported to disrupt cellulose $[25,26]$. To investigate whether CalkGH9T could benefit a fungal enzyme preparation, hydrolysis of RAC by a combination of CalkGH9T and a commercial fungal enzyme Ctec2 was tested (Figure 9). Here, the enzymatic reaction was performed at $\mathrm{pH} 7.4$ and $55^{\circ} \mathrm{C}$ with a substrate loading of $1 \%(w / v)$ RAC and a total protein load of $100 \mu \mathrm{g}$. The hydrolysis of RAC by Ctec2 alone $(100 \mu \mathrm{g})$ released reducing sugars after 15, 30, and $60 \mathrm{~min}$ of incubation. The supplementation of Ctec2 $(90 \mu \mathrm{g})$ with CalkGH9T $(10 \mu \mathrm{g})$ resulted in increased release of reducing sugars at all incubation times compared to Ctec 2 alone. The increase in reducing sugar release indicates that CalkGH9T can work in concert with $\mathrm{Ctec} 2$. This synergistic interaction can be explained by at least two mechanisms. First, CalkGH9T may bind to the insoluble RAC, and loosen and cleave cellulose chains, thereby creating new free chain ends for other enzymes, i.e., exoglucanases or cellobiohydrolases, present in Ctec2 to attack. Second, despite the 
limited activity on RAC, CalkGH9T may hydrolyze soluble cellodextrins produced by Ctec2 to short cello-oligomers, thus increasing the concentration of reducing ends.

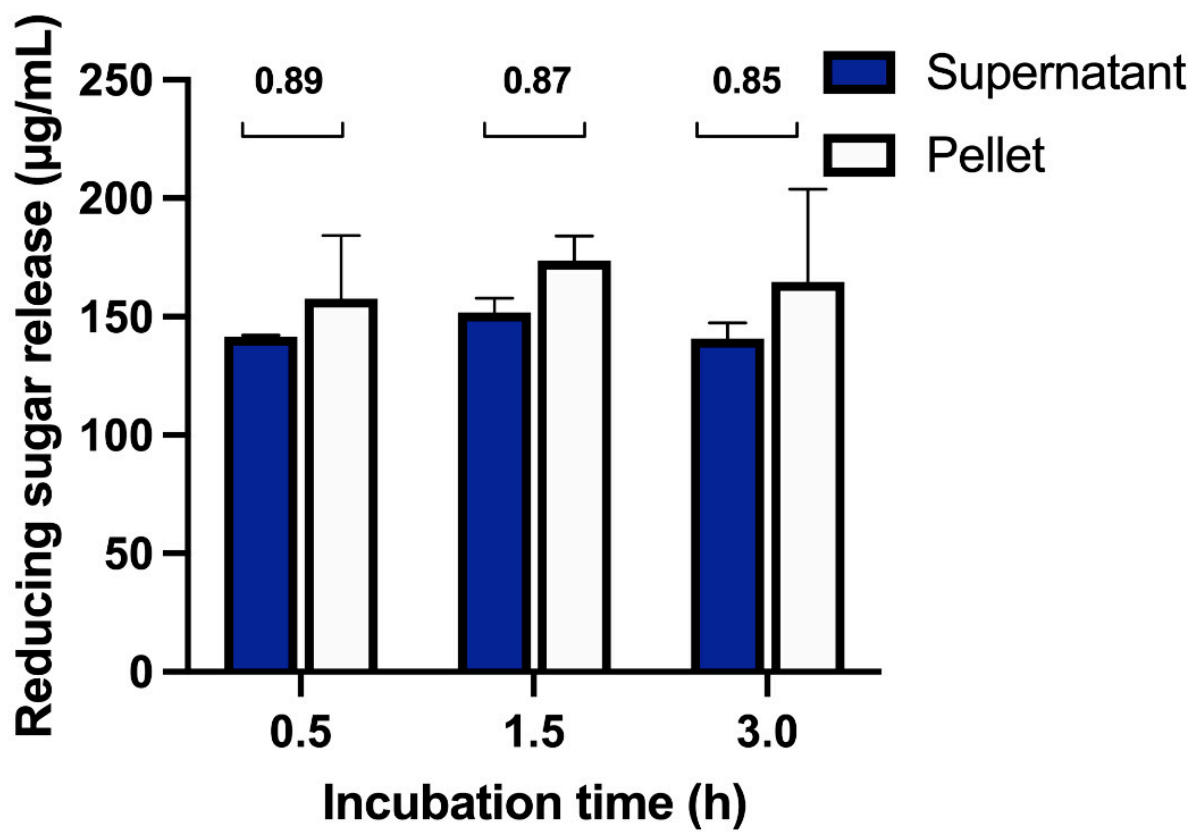

Figure 8. Processive activity test on RAC. Values are means and bars represent the standard deviations for three independent experiments.

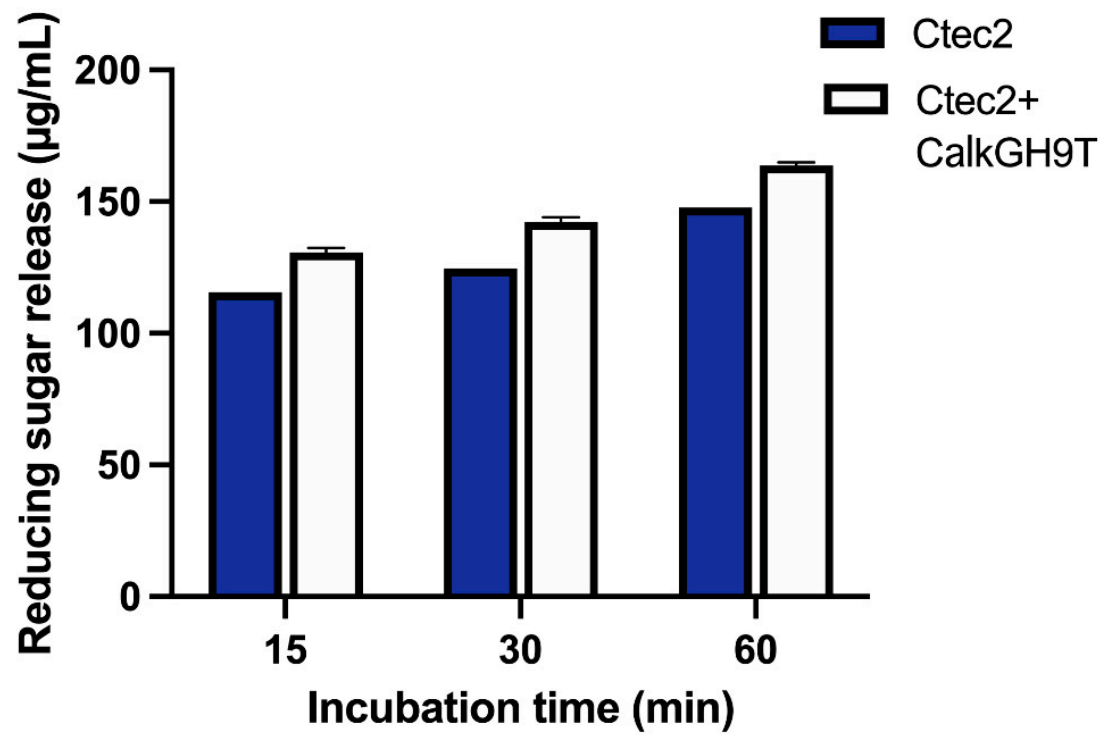

Figure 9. The effect of CalkGH9T addition to a commercial cellulase preparation Ctec2 on RAC hydrolysis. The enzymatic reaction was performed at $\mathrm{pH} 7.4$ and $55{ }^{\circ} \mathrm{C}$ with a substrate loading of $1 \%(w / v)$ RAC and a total protein load of $100 \mu \mathrm{g}$. The reaction with Ctec 2 alone $(100 \mu \mathrm{g}$ protein load) was used as a control. For supplementation of Ctec2 with CalkGH9T, Ctec2 was replaced with CalkGH9T by $10 \%$, corresponding to a load of $90 \mu \mathrm{g}$ Ctec 2 and $10 \mu \mathrm{g}$ CalkGH9T, respectively. Values are means and bars represent the standard deviations for three independent experiments.

3. Materials and Methods

3.1. DNA, Bacterial Strains, Plasmid, and Chemicals

The bacterial genomic DNA of C. alkalicellulosi DSM17461 ${ }^{\mathrm{T}}$ was prepared by Leibniz Institute DSMZ-German Collection of Microorganisms and Cell Cultures, Germany. 
E. coli competent cell strains NEB5 $\alpha$ and BL21 (DE3), used for cloning and protein expression, respectively, were purchased from New England BioLabs, Inc., (Ipswich, MA, USA). The expression vector pET28a(+) used for both cloning and protein expression and T4 DNA ligase were obtained from Novagen, (Madison, WI, USA). Restriction enzymes (i.e., NheI and XhoI)) were obtained from ThermoFisher Scientific, (Waltham, MA, USA). $4 \mathrm{M}$ carboxymethylcellulose (CMC), Azo-CMC, beechwood xylan, standard glucose and cellodextrins (G2-G6), and standard xylose and xylo-oligomers (X2-X6) were purchased from Megazyme, Ireland, and Avicel PH105 was purchased from Sigma-Aldrich Chemicals Co., USA. Thin layer chromatography plates (TLC silica gel $60 \mathrm{~F}_{254}, 20 \times 20$ ) were procured from Merck, (Kenilworth, NJ, USA). Regenerated amorphous cellulose (RAC) was prepared as described by Zhang, et al. [40].

\subsection{Gene Cloning and Recombinant DNA Techniques}

The gene CloalDRAFT_2759 present in the C.alkalicellulosi genome was predicted to encode a CalkGH9T protein. This gene without a signal peptide was amplified by PCR using specific primers. The primers were forward 5'-AATTAGCTAGCGATCCAGAGTACAACTTTGC$3^{\prime}$ and reverse $5^{\prime}$ - AATTACTCGAGTTAACGCGGCAGTTGTGGAA- $3^{\prime}$, in which the restriction sites for NheI and XhoI are underlined, respectively. The PCR program was initial denaturation at $98{ }^{\circ} \mathrm{C}$ for $30 \mathrm{~s}$, followed by 40 cycles of denaturation at $98{ }^{\circ} \mathrm{C}$ for $10 \mathrm{~s}$, annealing at $60{ }^{\circ} \mathrm{C}$ for $40 \mathrm{~s}$, elongation at $72{ }^{\circ} \mathrm{C}$ for $90 \mathrm{~s}$, and final extension at $72{ }^{\circ} \mathrm{C}$ for 5 min [36]. The PCR product was checked by gel electrophoresis using $0.8 \%(w / v)$ agarose. The amplified product with the target size was cut from the gel and purified by using a Qiagen gel extraction kit (Qiagen, New York, NY, USA). The purified product and plasmid pET28a $(+)$ were double digested with NheI and XhoI restriction enzymes and ligated with T4 DNA ligase (BioRad, Hercules, CA, USA). After ligation, the recombinant plasmid was transformed into E. coli NEB $5 \alpha$ competent cells. The transformed cells were grown on LB agar plate supplemented with kanamycin $(50 \mu \mathrm{g} / \mathrm{mL})$ at $37^{\circ} \mathrm{C}$ overnight. The positive recombinant clones were selected, and their recombinant DNA sequences were confirmed by means of colony PCR and DNA sequencing.

\subsection{Protein Expression and Purification}

The recombinant plasmid pET28a(+) containing a gene encoding CalkGH9T was transformed into E. coli BL21 (DE3) cells. The transformed cells were grown at $37^{\circ} \mathrm{C}$ in LB broth supplemented with kanamycin $(50 \mu \mathrm{g} / \mathrm{mL})$ and $2 \mathrm{mM} \mathrm{CaCl}_{2}$ to reach midexponential growth phase (optical density at $\left.600 \mathrm{~nm}\left(\mathrm{OD}_{600}\right) \sim 0.7-1.0\right)$. After that, the growth culture was supplemented with isopropyl-1-thio- $\beta$-D-galactopyranoside (IPTG) at a final concentration of $0.2 \mathrm{mM}$ to induce protein synthesis and further incubated at $16{ }^{\circ} \mathrm{C}$ overnight. The cells were harvested by centrifugation at $4200 \times g$ at $4{ }^{\circ} \mathrm{C}$ for $15 \mathrm{~min}$, and the cell pellets were then resuspended in $20 \mathrm{~mL}$ Tris buffer saline (TBS, $25 \mathrm{mM}$ Tris- $\mathrm{HCl}$, $137 \mathrm{mM} \mathrm{NaCl}, 2.7 \mathrm{mM} \mathrm{KCl}, \mathrm{pH}$ 7.4) containing $5 \mathrm{mM}$ imidazole and $300 \mathrm{mM} \mathrm{NaCl}$. The cell suspension was sonicated and centrifuged at $22,000 \times g$ at $4{ }^{\circ} \mathrm{C}$ for $30 \mathrm{~min}$ to separate cell debris.

The crude protein supernatant was mixed with Ni-NTA resin (Qiagen, New York, NY, USA), incubated at $4{ }^{\circ} \mathrm{C}$ for $1 \mathrm{~h}$ with gentle rotation, and loaded into a 20-mL Econo-Pack column (BioRad, Hercules, CA, USA). By gravitational flow, the column was washed with $100 \mathrm{~mL}$ washing buffer (TBS containing $30 \mathrm{mM}$ imidazole and $300 \mathrm{mM} \mathrm{NaCl}$ ). After washing, the protein was eluted with $16 \mathrm{~mL}$ elution buffer (TBS containing $250 \mathrm{mM}$ imidazole and $300 \mathrm{mM} \mathrm{NaCl}$ ). The eluted fraction was dialyzed against TBS at $4{ }^{\circ} \mathrm{C}$ overnight, and the dialyzed protein was determined for its purity on 10\% SDS-PAGE stained with InstantBlue coomassie stain (Expedeon, San Diego, CA, USA). The protein concentrations were determined by the absorbance at $280 \mathrm{~nm}$. The extinction coefficient of the protein was determined by use of the ProtParam tool on the EXPASY server (https: / / web.expasy.org/protparam/, accessed on 13 June 2019). 


\subsection{Enzyme Activity Assay}

The enzyme assay was performed in a total reaction volume of $200 \mu \mathrm{L}$. The reaction mixture consisted of $1 \%(w / v)$ substrate (i.e., CMC, RAC, BWX, and Avicel) and $0.25 \mu \mathrm{M}$ of CalkGH9T in $50 \mathrm{mM}$ TBS pH 7.4. The reaction mixture was incubated at $50{ }^{\circ} \mathrm{C}$ for $15 \mathrm{~min}$ (or 3-24 $\mathrm{h}$ for RAC and Avicel, respectively). The reaction was terminated by immersion in ice water and centrifuged at $13,000 \times \mathrm{g}$ at $4{ }^{\circ} \mathrm{C}$ for $10 \mathrm{~min}$ to separate the substrate from the soluble fraction. One hundred microliters of the soluble fraction was taken to a new 1.5-mL microcentrifuge tube and $150 \mu \mathrm{L}$ of dinitrosalicylic acid (DNS) [41] was added. The reaction mixture was boiled for $10 \mathrm{~min}$ and centrifuged at high speed. A sample was taken and measured at an absorbance of $540 \mathrm{~nm}$. The amount of reducing sugar released in the mixture was estimated using a glucose standard curve. One unit of enzyme was defined as the amount of enzyme that produces $1 \mu \mathrm{Mol}$ of glucose equivalent in $1 \mathrm{~min}$ under the assayed conditions.

\subsection{Effect of $\mathrm{pH}$ and Temperature}

The effect of $\mathrm{pH}$ on enzyme activity was analyzed by determining the activity at different $\mathrm{pH}$ values from $\mathrm{pH} 3.0-11.0$ at $55^{\circ} \mathrm{C}$ for $10 \mathrm{~min}$. Buffers $(50 \mathrm{mM})$ with different $\mathrm{pH}$ ranges were citrate-sodium citrate buffer for $\mathrm{pH}$ 3.0-7.0, Tris- $\mathrm{HCl}$ buffer for $\mathrm{pH}$ 7.0-9.0, and glycine- $\mathrm{NaOH}$ for $\mathrm{pH} 9.0-11.0$. The maximum activity at the corresponding $\mathrm{pH}$ was taken as $100 \%$. The $\mathrm{pH}$ stability assay was performed by incubating $5.5 \mu \mathrm{L}$ of the $11.5 \mu \mathrm{M}$ enzyme in $10 \mathrm{mM}$ of the buffers mentioned above at $30^{\circ} \mathrm{C}$ for $30 \mathrm{~min}$. After that, the enzyme solution was diluted, and the residual activity was measured under optimal assay conditions.

The effect of temperature on enzyme activity was tested by incubating $0.25 \mu \mathrm{M}$ enzyme in a $200-\mu \mathrm{L}$ reaction mixture containing $1 \%(w / v)$ substrate at a temperature range of $40-70{ }^{\circ} \mathrm{C}, \mathrm{pH} 7.4$ (TBS) for $10 \mathrm{~min}$. The maximum activity at the corresponding temperature was taken as $100 \%$. The thermal stability of the enzyme was determined by incubating $5.5 \mu \mathrm{L}$ of the $11.5 \mu \mathrm{M}$ enzyme at the temperatures of 40,50 , and $60^{\circ} \mathrm{C}$ for $0-24 \mathrm{~h}$. The enzyme solution was diluted, and the residual activity was determined under optimal assay conditions.

\subsection{Effect of Metal Ions, Salts, and Chemicals}

The effect of different metal ions (in the form of sulfate salts), including $\mathrm{Ca}^{2+}, \mathrm{Mg}^{2+}$, $\mathrm{Cu}^{2+}, \mathrm{Zn}^{2+}$, and chemicals, including chelating agent EDTA and urea, on enzyme activity were explored. Metal ions, EDTA, and urea were added to a final concentration of $1 \mathrm{mM}$ to a $200-\mu \mathrm{L}$ reaction mixture containing $0.25 \mu \mathrm{M}$ enzyme and $1 \%(w / v)$ substrate. The reaction was carried out at $55^{\circ} \mathrm{C}$, pH 7.4 (TBS) for $10 \mathrm{~min}$, and the residual activity was determined by measuring the reducing sugar released in the reaction mixture as described above. Substrate blanks with added metal ions, EDTA, and urea were run in parallel and assayed. The enzyme activity measured in the absence of metal ions and chemicals was taken as $100 \%$.

The effect of $\mathrm{NaCl}$ was investigated by adding different concentrations of $\mathrm{NaCl}(0-10 \%$, $w / v)$ to a $200-\mu \mathrm{L}$ reaction mixture containing $0.25 \mu \mathrm{M}$ enzyme and $1 \%(w / v)$ substrate. The reaction was carried out at $55^{\circ} \mathrm{C}, \mathrm{pH} 7.4$ (TBS) for $10 \mathrm{~min}$, and the residual activity was determined by measuring the reducing sugar released in the reaction mixture as described earlier.

\subsection{Analysis of the Hydrolysis Product}

The reaction mixture (total volume of $200 \mu \mathrm{L}$ ) containing $0.25 \mu \mathrm{M}$ enzyme and $1 \%$ $(w / v)$ substrate (i.e., CMC and RAC) was assayed under optimal conditions with varying times from $15 \mathrm{~min}$ to $16 \mathrm{~h}$. The reaction was stopped at specific time intervals by boiling for $5 \mathrm{~min}$ and centrifuging at $13,000 \times g$ at $4{ }^{\circ} \mathrm{C}$ for $10 \mathrm{~min}$ to remove the undigested substrate. The soluble fraction was transferred to a new tube, and $4 \mu \mathrm{L}$ of the soluble fraction was mixed with $4 \mu \mathrm{L}$ of absolute ethanol. The mixed sample $(8 \mu \mathrm{L})$ was spotted 
on TLC plates. The plates were immersed in a TLC chamber containing $n$-butanol:acetic acid:water at a ratio of 2:1:1 as the mobile phase. After sufficient migration of the mobile phase, the TLC plate was removed from the chamber, dried in a hood, and sprayed with visualization solution containing $1 \mathrm{~mL}$ aniline, $1 \mathrm{~g} \alpha$-diphenylamine, $50 \mathrm{~mL}$ acetone, and $7.5 \mathrm{~mL}$ phosphoric acid. The TLC plate was heated at $90^{\circ} \mathrm{C}$ in a hot air oven for $5 \mathrm{~min}$. Five microliters of a series of sugars (G1-G6, $0.2 \mathrm{mg} / \mathrm{mL}$ each) was run in parallel and used as a standard. Hydrolysis of cellodextrins (G2-G6) was performed as with the hydrolysis of polysaccharides described above, except that the final concentration of the substrate was $0.2 \mathrm{mg} / \mathrm{mL}$ and the incubation time was $15 \mathrm{~min}$.

\subsection{Cohesin-Dockerin Interaction Test Using Enzyme-Linked Immunosorbent Assay (ELISA)}

Affinity-based ELISA was performed as described previously by Phitsuwan, et al. [21]. In brief, the 96-well plates (NuNc, A/S, Roskilde, Denmark) were coated with the fusion protein Xyn-Doc I of CalkGH9T at a concentration of $1 \mu \mathrm{g} / \mathrm{mL}$, and different concentrations of CBM-cohesins of ScaA ranging from 0.001 to $1000 \mathrm{ng} / \mathrm{mL}$ were applied on the coated plates to detect cohesin-dockerin interactions. The interactions were examined immunochemically by using anti-CBM primary antibody and horseradish peroxidase (HRP)-labeled secondary antibody in the presence of chromogenic substrate TMB $\left(3,3^{\prime}, 5,5^{\prime}-\right.$ tetramethylbenzidine, Dako, Glostrup Municipality of Glostrup, Denmark). The anti-CBM primary antibody was prepared from rabbit and diluted 1:10000 in blocking buffer [42]. The reaction product (color formation) was measured at the absorbance of $450 \mathrm{~nm}$.

\subsection{Polysaccharide Binding Assay}

Enzyme $(0.25 \mu \mathrm{M})$ was mixed with $1 \%(w / v)$ polysaccharides in TBS in a final volume of $200 \mu \mathrm{L}$ in a 1.5-mL microcentrifuge tube. The reaction tube was gently rotated, and the incubation temperature was maintained at $4{ }^{\circ} \mathrm{C}$ for $1 \mathrm{~h}$. After binding, the reaction mixture was centrifuged at $13,000 \times \mathrm{g}$ at $4{ }^{\circ} \mathrm{C}$ for $10 \mathrm{~min}$. All of the soluble fraction was transferred to a new 1.5-mL microcentrifuge tube, and this fraction was considered "unbound protein". The substrate pellet was washed with $500 \mu \mathrm{L}$ TBS by vortex mixer and then centrifuged at $13,000 \times g$ at $4{ }^{\circ} \mathrm{C}$ for $10 \mathrm{~min}$. This washing step was repeated three times. The washed pellet was then mixed with $4 \times$ SDS sample buffer (Bio-Rad, Hercules, CA, USA), to a final volume of $60 \mu \mathrm{L}$ and boiled for $10 \mathrm{~min}$. The protein associated with the pellet was considered "bound protein." For unbound protein, $45 \mu \mathrm{L}$ of the soluble fraction was mixed with $15 \mu \mathrm{L}$ of $4 \times$ SDS sample buffer and boiled for $10 \mathrm{~min}$. Thirty microliters of both unbound and bound proteins were taken and analyzed on 10\% SDS-PAGE. The protein intensity in SDS-PAGE was calculated using ImageJ gel analysis [43].

\subsection{Processive Activity Assay}

The content of reducing ends in the soluble and insoluble fractions was determined using RAC as a substrate. Different concentrations of enzyme were added to a 1.5-mL microcentrifuge tube containing $1 \%(w / v)$ RAC in TBS (final volume of $200 \mathrm{~mL}$ ). The reaction mixture was incubated at $55{ }^{\circ} \mathrm{C}$ for different incubation times. After incubation, the reaction tube was centrifuged at $13,000 \times \mathrm{g}$ at $4{ }^{\circ} \mathrm{C}$ for $10 \mathrm{~min}$, and the supernatant was removed, of which $100 \mu \mathrm{L}$ was taken for measurement of reducing ends (soluble fraction) by the DNS method. The pellet was washed three times with $500 \mu \mathrm{L}$ TBS by centrifugation at $13,000 \times g$ at $4{ }^{\circ} \mathrm{C}$ for $5 \mathrm{~min}$. After washing, the pellet was resuspended in $100 \mu \mathrm{L}$ TBS and taken for measurement of reducing ends (insoluble fraction) by the DNS method.

\section{Conclusions}

CalkGH9T of C. alkalicellulosi is a GH9 endoglucanase with a modular architecture. The presence of a dockerin sequence and the affinity interaction between the dockerin and the cohesin modules of the primary scaffold prove CalkGH9T is a cellulosomal enzyme. The enzyme actively hydrolyzed CMC but had low activity on RAC and lacked activity on Avicel. However, the existence of the CBM3 allowed CalkGH9T to bind tightly to 
Avicel. The production of $40 \%$ reducing ends on insoluble RAC by CalkGH9T indicates its non-processive activity. Cellotetraose was the major hydrolysis product of CMC and RAC. The addition of CalkGH9T to commercial cellulase Ctec2 increased reducing sugar yield during RAC hydrolysis. Our study indicates an important role of CalkGH9T in cellulose degradation.

Supplementary Materials: The following are available online at https:/ / www.mdpi.com/article/10 .3390 / catal11081011/s1, Figure S1: translated amino acid sequence and a calculated molecular weight and a $\mathrm{pI}$ value of CalkGH9T analysed by ProtParam online tool, Figure S2: 10\% SDS-PAGE analysis of CalkGH9T expression and purification. Lane: $\mathrm{M}$, molecular weight marker (PageRuler ${ }^{\mathrm{TM}}$ prestained protein ladder, 10 to $180 \mathrm{kDa}$ ). Lane: 1-7, the eluted proteins from 2-mL collected fractions. Each well was loaded with $20 \mu \mathrm{L}$ of individual eluted protein fractions, and Figure S3: Reducing sugar release from RAC by CalkGH9T. Values are means and bars represent the standard deviations for three independent experiments, Figure S4: TLC analysis of hydrolysis products generated by $0.25 \mu \mathrm{M}$ CalkGH9T using cellodextrins with a degree of polymerization of 2-6 (G2-G6) as the substrates for 16-h incubations. S, standards of glucose and cellodextrins with a degree of polymerization of 2-6 (G2-G6). E, CalkGH9T. G2, G3, G4, G5, and G6 represent a reaction control (a reaction mixture containing a substrate and a denatured enzyme). G2 + E, G3 + E, G4 + E, G5 + E, and G6 + E represent enzymatic reactions. The enzymatic reactions were performed at $\mathrm{pH} 7.4$ and $55^{\circ} \mathrm{C}$.

Author Contributions: Conceptualization, P.P.; methodology, P.P.; validation, P.P., S.L., and T.S.; formal analysis, S.L. and T.S.; investigation, P.P., S.L., and T.S.; resources, P.P. and K.R.; data curation, P.P.; writing — original draft preparation, review and editing, P.P.; funding acquisition, P.P. and K.R. All authors have read and agreed to the published version of the manuscript.

Funding: This research was funded by the Thailand Research Fund, grant number MRG6180076, and the Biodiversity-Based Economy Development Office (Public Organization), Thailand. The APC was funded by Thailand Science Research and Innovation (TSRI), Basic Research Fund: Fiscal year 2021 under project number 64A306000039.

Data Availability Statement: All data are provided by the manuscript and the Supporting Information. Relevant data are available from the authors on request.

Acknowledgments: We gratefully thank Edward A. Bayer (Weizmann Institute of Science, Israel) for providing genomic information of $C$. alkalicellulosi.

Conflicts of Interest: The authors declare no conflict of interest.

\section{References}

1. Hamid, S.B.A.; Islam, M.M.; Das, R. Cellulase biocatalysis: Key influencing factors and mode of action. Cellulose 2015, 22, 21572182. [CrossRef]

2. Phitsuwan, P.; Sakka, K.; Ratanakhanokchai, K. Improvement of lignocellulosic biomass in planta:a review of feedstocks, biomass recalcitrance, and strategic manipulation of ideal plants designed for ethanol production and processability. Biomass Bioenergy 2013, 58, 390-405. [CrossRef]

3. Gupta, V.K.; Steindorff, A.S.; de Paula, R.G.; Silva-Rocha, R.; Mach-Aigner, A.R.; Mach, R.L.; Silva, R.N. The post-genomic era of Trichoderma reesei: What's next? Trends Biotechnol. 2016, 34, 970-982. [CrossRef]

4. Akram, F.; Haq, I.u.; Imran, W.; Mukhtar, H. Insight perspectives of thermostable endoglucanases for bioethanol production: A review. Renew. Energy 2018, 122, 225-238. [CrossRef]

5. Beckham, G.T.; Ståhlberg, J.; Knott, B.C.; Himmel, M.E.; Crowley, M.F.; Sandgren, M.; Sørlie, M.; Payne, C.M. Towards a molecular-level theory of carbohydrate processivity in glycoside hydrolases. Curr. Opin. Biotechnol. 2014, 27, 96-106. [CrossRef] [PubMed]

6. Ravachol, J.; Borne, R.; Tardif, C.; De Philip, P.; Fierobe, H.P. Characterization of all family-9 glycoside hydrolases synthesized by the cellulosome-producing bacterium Clostridium cellulolyticum. J. Biol. Chem. 2014, 289, 7335-7348. [CrossRef] [PubMed]

7. Arai, T.; Kosugi, A.; Chan, H.; Koukiekolo, R.; Yukawa, H.; Inui, M.; Doi, R.H. Properties of cellulosomal family 9 cellulases from Clostridium cellulovorans. Appl. Microbiol. Biotechnol. 2006, 71, 654-660. [CrossRef]

8. Petkun, S.; Jindou, S.; Shimon, L.J.W.; Rosenheck, S.; Bayer, E.A.; Lamed, R.; Frolow, F. Structure of a family 3b' carbohydratebinding module from the Cel9V glycoside hydrolase from Clostridium thermocellum: Structural diversity and implications for carbohydrate binding. Acta Crystallogr. D Biol. Crystallogr. 2010, 66, 33-43. [CrossRef]

9. Schröder, C.; Burkhardt, C.; Busch, P.; Schirrmacher, G.; Claren, J.; Antranikian, G. Characterization of a theme C glycoside hydrolase family 9 endo- $\beta$-Glucanase from a biogas reactor metagenome. Protein J. 2018, 37, 454-460. [CrossRef] 
10. Zhang, K.D.; Li, W.; Wang, Y.F.; Zheng, Y.L.; Tan, F.C.; Ma, X.Q.; Yao, L.S.; Bayer, E.A.; Wang, L.S.; Li, F.L. Processive degradation of crystalline cellulose by a multimodular endoglucanase via a wirewalking mode. Biomacromolecules 2018, 19, 1686-1696. [CrossRef]

11. Mingardon, F.; Bagert, J.D.; Maisonnier, C.; Trudeau, D.L.; Arnold, F.H. Comparison of family 9 cellulases from mesophilic and thermophilic bacteria. Appl. Environ. Microbiol. 2011, 77, 1436-1442. [CrossRef]

12. Qi, M.; Jun, H.S.; Forsberg, C.W. Cel9D, an atypical 1,4- $\beta$-D-glucan glucohydrolase from Fibrobacter succinogenes: Characteristics, catalytic residues, and synergistic interactions with other cellulases. J. Bacteriol. 2008, 190, 1976-1984. [CrossRef]

13. Li, Y.; Irwin, D.C.; Wilson, D.B. Processivity, substrate binding, and mechanism of cellulose hydrolysis by Thermobifida fusca Cel9A Appl. Environ. Microbiol. 2007, 73, 3165-3172. [CrossRef]

14. Gilad, R.; Rabinovich, L.; Yaron, S.; Bayer, E.A.; Lamed, R.; Gilbert, H.J.; Shoham, Y. Cell, a noncellulosomal family 9 enzyme from Clostridium thermocellum, is a processive endoglucanase that degrades crystalline cellulose. J. Bacteriol. 2003, 185, 391-398. [CrossRef] [PubMed]

15. Jeng, W.Y.; Liu, C.I.; Lu, T.J.; Lin, H.J.; Wang, N.C.; Wang, A.H.J. Crystal structures of the C-terminally truncated endoglucanase Cel9Q from Clostridium thermocellum complexed with cellodextrins and Tris. ChemBioChem 2019, 20, 295-307. [CrossRef] [PubMed]

16. Jindou, S.; Xu, Q.; Kenig, R.; Shulman, M.; Shoham, Y.; Bayer, E.A.; Lamed, R. Novel architecture of family-9 glycoside hydrolases identified in cellulosomal enzymes of Acetivibrio cellulolyticus and Clostridium thermocellum. FEMS Microbiol. Lett. 2006, 254, 308-316. [CrossRef]

17. Artzi, L.; Morag, E.; Barak, Y.; Lamed, R.; Bayer, E.A. Clostridium clariflavum: Key cellulosome players are revealed by proteomic analysis. mBio 2015, 6, e00411-e00415. [CrossRef]

18. Zvereva, E.A.; Fedorova, T.V.; Kevbrin, V.V.; Zhilina, T.N.; Rabinovich, M.L. Cellulase activity of a haloalkaliphilic anaerobic bacterium, strain Z-7026. Extremophiles 2006, 10, 53-60. [CrossRef] [PubMed]

19. Zhilina, T.N.; Kevbrin, V.V.; Tourova, T.P.; Lysenko, A.M.; Kostrikina, N.A.; Zavarzin, G.A. Clostridium alkalicellum sp. nov., an obligately alkaliphilic cellulolytic bacterium from a soda lake in the Baikal region. Microbiology 2005, 74, 557-566. [CrossRef]

20. Artzi, L.; Bayer, E.A.; Moraïs, S. Cellulosomes: Bacterial nanomachines for dismantling plant polysaccharides. Nat. Rev. Microbiol. 2017, 15, 83-95. [CrossRef] [PubMed]

21. Phitsuwan, P.; Moraïs, S.; Dassa, B.; Henrissat, B.; Bayer, E.A. The cellulosome paradigm in an extreme alkaline environment. Microorganisms 2019, 7, 347. [CrossRef]

22. Madeira, F.; Park, Y.M.; Lee, J.; Buso, N.; Gur, T.; Madhusoodanan, N.; Basutkar, P.; Tivey, A.R.N.; Potter, S.C.; Finn, R.D.; et al. The EMBL-EBI search and sequence analysis tools APIs in 2019. Nucleic Acids Res. 2019, 47, W636-W641. [CrossRef]

23. Robert, X.; Gouet, P. Deciphering key features in protein structures with the new ENDscript server. Nucleic Acids Res. 2014, 42, W320-W324. [CrossRef] [PubMed]

24. Kurokawa, J.; Hemjinda, E.; Arai, T.; Kimura, T.; Sakka, K.; Ohmiya, K. Clostridium thermocellum cellulase CelT, a family 9 endoglucanase without an Ig-like domain or family 3c carbohydrate-binding module. Appl. Microbiol. Biotechnol. 2002, 59, 455-461. [CrossRef] [PubMed]

25. Petkun, S.; Rozman Grinberg, I.; Lamed, R.; Jindou, S.; Burstein, T.; Yaniv, O.; Shoham, Y.; Shimon, L.J.; Bayer, E.A.; Frolow, F. Reassembly and co-crystallization of a family 9 processive endoglucanase from its component parts: Structural and functional significance of the intermodular linker. PeerJ 2015, 3, e1126. [CrossRef] [PubMed]

26. Kim, S.J.; Kim, S.H.; Shin, S.K.; Hyeon, J.E.; Han, S.O. Mutation of a conserved tryptophan residue in the CBM3c of a GH9 endoglucanase inhibits activity. Int. J. Biol. Macromol. 2016, 92, 159-166. [CrossRef]

27. Montanier, C.; Money, V.A.; Pires, V.M.; Flint, J.E.; Pinheiro, B.A.; Goyal, A.; Prates, J.A.; Izumi, A.; Stalbrand, H.; Morland, C.; et al. The active site of a carbohydrate esterase displays divergent catalytic and noncatalytic binding functions. PLoS Biol. 2009, 7, e71. [CrossRef]

28. Gao, Z.; Ruan, L.; Chen, X.; Zhang, Y.; Xu, X. A novel salt-tolerant endo- $\beta$-1,4-glucanase Cel5A in Vibrio sp. G21 isolated from mangrove soil. Appl. Microbiol. Biotechnol. 2010, 87, 1373-1382. [CrossRef]

29. Percival Zhang, Y.H.; Himmel, M.E.; Mielenz, J.R. Outlook for cellulase improvement: Screening and selection strategies. Biotechnol. Adv. 2006, 24, 452-481. [CrossRef]

30. Eckert, K.; Ernst, H.A.; Schneider, E.; Larsen, S.; Lo Leggio, L. Crystallization and preliminary X-ray analysis of Alicyclobacillus acidocaldarius endoglucanase CelA. Acta Crystallogr. D Biol. Crystallogr. 2003, 59, 139-141. [CrossRef]

31. Yu, H.Y.; Li, X. Alkali-stable cellulase from a halophilic isolate, Gracilibacillus sp. SK1 and its application in lignocellulosic saccharification for ethanol production. Biomass Bioenergy 2015, 81, 19-25. [CrossRef]

32. Xue, D.S.; Liang, L.Y.; Lin, D.Q.; Gong, C.J.; Yao, S.J. Halostable catalytic properties of exoglucanase from a marine Aspergillus niger and secondary structure change caused by high salinities. Process Biochem. 2017, 58, 85-91. [CrossRef]

33. Danson, M.J.; Hough, D.W. The structural basis of protein halophilicity. Comp. Biochem. Physiol. A Physiol. 1997, 117, 307-312. [CrossRef]

34. Artzi, L.; Dassa, B.; Borovok, I.; Shamshoum, M.; Lamed, R.; Bayer, E.A. Cellulosomics of the cellulolytic thermophile Clostridium clariflavum. Biotechnol. Biofuels 2014, 7, 100. [CrossRef] [PubMed]

35. Hamberg, Y.; Ruimy-Israeli, V.; Dassa, B.; Barak, Y.; Lamed, R.; Cameron, K.; Fontes, C.M.; Bayer, E.A.; Fried, D.B. Elaborate cellulosome architecture of Acetivibrio cellulolyticus revealed by selective screening of cohesin-dockerin interactions. PeerJ 2014, 2, e636. [CrossRef] 
36. Zhang, X.Z.; Sathitsuksanoh, N.; Zhang, Y.H.P. Glycoside hydrolase family 9 processive endoglucanase from Clostridium phytofermentans: Heterologous expression, characterization, and synergy with family 48 cellobiohydrolase. Bioresour. Technol. 2010, 101, 5534-5538. [CrossRef] [PubMed]

37. Irwin, D.C.; Spezio, M.; Walker, L.P.; Wilson, D.B. Activity studies of eight purified cellulases: Specificity, synergism, and binding domain effects. Biotechnol. Bioeng. 1993, 42, 1002-1013. [CrossRef]

38. Kruus, K.; Wang, W.K.; Ching, J.; Wu, J.H.D. Exoglucanase activities of the recombinant Clostridium thermocellum CelS, a major cellulosome component. J. Bacteriol. 1995, 177, 1641-1644. [CrossRef]

39. Payne, C.M.; Knott, B.C.; Mayes, H.B.; Hansson, H.; Himmel, M.E.; Sandgren, M.; Ståhlberg, J.; Beckham, G.T. Fungal cellulases. Chem. Rev. 2015, 115, 1308-1448. [CrossRef]

40. Zhang, Y.H.P.; Cui, J.; Lynd, L.R.; Kuang, L.R. A Transition from cellulose swelling to cellulose dissolution by 0 -phosphoric acid: evidence from enzymatic hydrolysis and supramolecular structure. Biomacromolecules 2006, 7, 644-648. [CrossRef] [PubMed]

41. Miller, G.L. Use of dinitrosalicylic acid reagent for determination of reducing sugar. Anal. Chem. 1959, 31, 426-428. [CrossRef]

42. Barak, Y.; Handelsman, T.; Nakar, D.; Mechaly, A.; Lamed, R.; Shoham, Y.; Bayer, E.A. Matching fusion protein systems for affinity analysis of two interacting families of proteins: The cohesin-dockerin interaction. J. Mol. Recognit. 2005, 18, 491-501. [CrossRef] [PubMed]

43. Schneider, C.A.; Rasband, W.S.; Eliceiri, K.W. NIH Image to ImageJ: 25 years of image analysis. Nat. Methods $2012,9,671-675$. [CrossRef] [PubMed] 